\title{
Equilibrium, Kinetics, and Thermodynamics of Remazol Brilliant Blue R Dye Adsorption onto Activated Carbon Prepared from Pinang Frond
}

\author{
Mohd Azhar Ahmad, Safarudin Gazali Herawan, and Ahmad Anas Yusof \\ Faculty of Mechanical Engineering, Universiti Teknikal Malaysia Melaka, Hang Tuah Jaya, 76100 Durian Tunggal, Melaka, Malaysia \\ Correspondence should be addressed to Mohd Azhar Ahmad; azharahmad.utem@gmail.com
}

Received 17 February 2014; Accepted 11 March 2014; Published 23 March 2014

Academic Editors: Y. He and J. Hu

Copyright (C) 2014 Mohd Azhar Ahmad et al. This is an open access article distributed under the Creative Commons Attribution License, which permits unrestricted use, distribution, and reproduction in any medium, provided the original work is properly cited.

\begin{abstract}
The adsorption of remazol brilliant blue R (RBBR) dye on pinang frond based activated carbon (PF-AC) was investigated in a batch process. The effects of initial dye concentration, contact time, solution temperature, and solution $\mathrm{pH}$ were evaluated. The adsorption equilibrium and kinetic were found to follow Freundlich isotherm models and pseudo-second-order kinetic model, respectively. The mechanism of the adsorption process was found from the intraparticle diffusion model. Result from adsorption thermodynamic show that interaction for RBBR dye was found to be feasible, nonspontaneous, and endothermic. The results indicated that the PF$A C$ is very effective for the RBBR adsorption from aqueous solution.
\end{abstract}

\section{Introduction}

Around 10,000 different dyes are produced annually from various industrial process which weigh approximately 0.7 million tons [1]. Dyes have a synthetic origin and complex aromatic molecular structures. It is estimated that $10-15 \%$ of the dyes are lost in the effluent during dyeing process [2]. In the textile industry, effluents from the dyeing and finishing processes are known to contain colour, a large amount of suspended organic solids and possibly heavy metals such as $\mathrm{Cr}, \mathrm{Ni}$, and $\mathrm{Cu}$ [3]. Dyes are inert and difficult to biodegrade and decolorize when discharged into waste streams. Hence, the presence of dyes into streams and rivers constitutes a source of water pollution that cannot be neglected [4].

In textile industry, there are several varieties of dyes used such as reactive dyes, direct dyes, disperse dyes, acid dyes, basic dyes, and vat dyes. Almost $45 \%$ of textile produced worldwide belongs to the reactive dyes [5]. Remazol brilliant blue R (RBBR), remazol black (RB), and remazol brilliant violet $5 R(R B V)$ are the example of reactive dyes. They have the favorable characteristics of bright color, simple application techniques, low energy consumption dyeing process, and high solubility in water. The discharge of these wastewaters reactive dyes into receiving streams are highly carcinogenic and possess toxic to organism [6]. Many studies have been conducted on the toxicity of dyes and their impact on the ecosystem $[7,8]$. Therefore, removal of such dyes from wastewater is very important to the environment.

Several of successful treatment systems have been designed such as flocculation, coagulation, precipitation, adsorption, membrane filtration, electrochemical techniques, ozonization, sedimentation, reverse osmosis, fungal degradation, and photodegradation [9] but the adsorption onto activated carbon has been found to offer the best potential techniques for removal of dyes from aqueous solution in terms of methodology, its capability for efficiently adsorbing a broad range of different types of adsorbates, simplicity design of adsorber, and easy recovery/reuse of adsorbent [10].

In the last few years, activated carbon was widely used in removal dyes from textile effluent which had relatively a very high adsorption capacity and is widely used as an adsorbent in many industrial processes [11, 12]. The high production costs of those commercial activated carbons have limited their application [13]. However, due to the relatively high 
cost of activated carbon, other sources of activated carbons precursor were investigated especially from agricultural byproducts which are abundance and available.

For example, pinang or Areca catechu in its scientific name is a tropical tree which belongs to the palm family. It mainly grows in East Africa, Arabian Peninsula and Asia. However, pinang frond which is part of this plant is considered as waste and usually disposed as solid waste [14]. The use of pinang frond (PF) as feedstock for activated carbon production would turn the pinang frond into value added commodities and this raw material is renewable and potentially less expensive to manufacture.

The purpose of this work was to prepare activated carbon from pinang frond and to find out the possibility of using this activated carbon as low-cost adsorbent for the removal of RBBR dye from aqueous solution. The equilibrium, kinetic and thermodynamics data of the adsorption were then studied to understand the adsorption.

\section{Materials and Methods}

2.1. Material. Remazol brilliant blue R, RBBR, supplied by Sigma-Aldrich (M) Sdn Bhd, Malaysia, was used as an adsorbate. RBBR has a chemical formula of $\mathrm{C}_{22} \mathrm{H}_{16} \mathrm{~N}_{2} \mathrm{Na}_{2} \mathrm{O}_{11} \mathrm{~S}_{3}$ with molecular weight of $626.54 \mathrm{~g} / \mathrm{mol}$. The chemical structure of the dye is shown in Figure 1.

Deionized water supplied by USF ELGA water treatment system was used to prepare all the reagents and solutions. Technical nitrogen, $\mathrm{N}_{2}$ (purity $99.99 \%$ ) and carbon dioxide, and $\mathrm{CO}_{2}$ gaseous were supplied by Air Product (M) Sdn Bhd. The pinang frond was obtained from Kota Kuala Muda, Sungai Petani, Kedah Malaysia.

\subsection{Preparation and Characterization of Activated Carbon.} Pinang frond was cut into small pieces and dried to remove the moisture content. The dried pinang frond was loaded in a stainless steel vertical tubular reactor placed in a tube furnace. The ramp temperature was $20^{\circ} \mathrm{C} / \mathrm{min}$ to the final temperature of $800^{\circ} \mathrm{C}$ under $\mathrm{N}_{2}$ flow of $150 \mathrm{~mL} / \mathrm{min}$. Once the final temperature was reached, the nitrogen gas flow was switched to carbon dioxide and activation was continued for 3 hours. The activated product (PF-AC) was then cooled down to room temperature under nitrogen flow. The sample produced was stored in air-tight container for further characterization and adsorption studies. The detail of preparation was described in the [14].

The textual characteristic PF-AC was carried out from the adsorption isotherms of nitrogen at $77 \mathrm{~K}$ by using Micromeritics (Model ASAP 2020, USA). The surface area was determined using the Brunauer-Emmet-Teller (BET) equation which is the most usual standard procedure used when characterizing an activated carbon. It was found that the BET surface area, average pore diameter, and pore volume of the PF-AC were $958.23 \mathrm{~m}^{2} / \mathrm{g}, 2.32 \mathrm{~nm}$, and $0.5469 \mathrm{~cm}^{3} / \mathrm{g}$, respectively [14].

2.3. Preparation of Stock and Dye Solutions. $1.0 \mathrm{~g}$ of dye powder was dissolved in $1000 \mathrm{~mL}$ of deionized water, respectively,<smiles>Nc1c(S(=O)(=O)O[Na])cc(Nc2cccc(S(=O)(=O)CCOS(=O)(=O)O[Na])c2)c2c1C(=O)c1ccccc1C2=O</smiles>

FIgURE 1: Chemical structure of RBBR.

to prepare the concentration of $1 \mathrm{~g} / \mathrm{L}$ dye solution. Solution of different initial concentrations $(50,100,200,300,400$, and $500 \mathrm{mg} / \mathrm{L}$ ) were prepared by dilution process of initial stock solution into $200 \mathrm{~mL}$ of deionized water.

2.4. Analysis of the Samples. Double-beam UV-visible spectrophotometer (Model Shimadzu UV-1800, Japan) was used to measure the concentration of the adsorbates. The maximum wavelength of the RBBR was $590 \mathrm{~nm}$. Calibration curve for RBBR dye concentration was reproducible and measured to assure the homogeneity and linear over the concentration range used in this work.

2.5. Batch Equilibrium Studies. Batch equilibrium studies were used to determine the adsorption of RBBR on the PFAC. The measure of adsorption at equilibrium $q_{e}(\mathrm{mg} / \mathrm{g})$ was calculated by

$$
q_{e}=\frac{\left(C_{0}-C_{e}\right) V}{W},
$$

where $C_{0}$ and $C_{e}(\mathrm{mg} / \mathrm{L})$ are the liquid-phase concentrations of RBBR dye at initial and at equilibrium, respectively. $V$ is the volume of the solution and $W$ is the mass of PF-AC used. The effect of the RBBR initial concentration, solution temperature, and solution $\mathrm{pH}$ on the adsorption uptakes was investigated. $0.2 \mathrm{~g}$ of the PF-AC was added into $200 \mathrm{~mL}$ adsorbate solution in Erlenmeyer flasks. The flasks were placed in an isothermal water bath shaker with rotation speed of $120 \mathrm{rpm}$.

2.5.1. Effect of RBBR Initial Concentration and Contact Time. The dye solutions at various initial concentrations of 50, 100, $200,300,400$, and $500 \mathrm{mg} / \mathrm{L}$ were placed in an isothermal water bath shaker. The temperature and rotation speed of water bath shaker were set at $30^{\circ} \mathrm{C}$ and $120 \mathrm{rpm}$, respectively, for 24 hours. The solution $\mathrm{pH}$ was kept original without any $\mathrm{pH}$ adjustment.

2.5.2. Effect of Solution Temperature. The effect of solution temperature on the adsorption process was studied by varying adsorption temperature at 30,45 , and $60^{\circ} \mathrm{C}$ by adjusting the temperature controller on the water bath shaker. The dye solution was kept at concentration of $100 \mathrm{mg} / \mathrm{L}$. The solution $\mathrm{pH}$ and other parameters were kept constant with no adjustment. 
2.5.3. Effect of Solution $\mathrm{pH}$. The initial $\mathrm{pH}$ solution of adsorbate was varying from 3 to 11 by using $0.1 \mathrm{M} \mathrm{HCl}$ and/or $0.1 \mathrm{M} \mathrm{NaOH}$. The dye concentration and temperature were kept at $100 \mathrm{mg} / \mathrm{L}$ and $30^{\circ} \mathrm{C}$, respectively. The percentage of dye removal was calculated by

$$
\operatorname{Removal}(\%)=\frac{\left(C_{0}-C_{e}\right)}{C_{0}} \times 100,
$$

where $C_{0}$ and $C_{e}$ in $\mathrm{mg} / \mathrm{L}$ are the liquid-phase concentrations of the adsorbate at initial and at equilibrium concentrations, respectively.

2.6. Batch Kinetic Studies. The batch kinetic studies followed the same procedure as batch equilibrium tests but the reading of aqueous concentration samples were taken at preset time interval. The RBBR concentration was similarly measured. The RBBR uptake at any time $q_{t}(\mathrm{mg} / \mathrm{g})$ was calculated by

$$
q_{t}=\frac{\left(C_{0}-C_{t}\right) V}{W},
$$

where $C_{t}(\mathrm{mg} / \mathrm{l})$ is the liquid-phase concentration of RBBR at any arbitrary time, $t(\mathrm{~h})$.

\section{Results and Discussion}

3.1. Effect of Contact Time and Initial Concentration of Adsorbate. Figure 2 shows that the adsorption uptakes of RBBR increase with increase in RBBR concentration. This phenomenon was due to increase in the driving force of the concentration gradient as an increase in the initial dye concentration [15]. The RBBR adsorption at equilibrium increased from 43.8 to $204.0 \mathrm{mg} / \mathrm{g}$ as the initial dye concentration increased from 50 to $500 \mathrm{mg} / \mathrm{L}$. At the first stage of 2 hours, the adsorption of RBBR was fast due to the availability of a large number of surface sites. However the adsorption gradually became slower until it reaches the equilibrium where no more dye can be adsorbed from the solution. At this point, the remaining surface of sites was difficult to be filled and the repulsion between the solute molecules of the solid and bulk phases occurred [16]. Similar phenomenon with Bello et al. [17] and Din et al. [18] which stated that the adsorption reached equilibrium within 24 hours in their experiments by using agriculture waste based activated carbon.

\subsection{Effect of Solution Temperature on RBBR Adsorption.} Figure 3 shows the effect of solution temperature on the RBBR dye uptake considered at $100 \mathrm{mg} / \mathrm{L}$ initial concentration. The removal on RBBR was slightly increased with increase of the solution temperature from 30 to $60^{\circ} \mathrm{C}$ which indicates that the adsorption process was in endothermic nature. Increasing the temperature has increased the diffusion of dye molecule to across the external and internal boundary layer of sample due to decrease in solution viscosity [19]. In addition, at higher temperature more dye molecules have sufficient energy to undergo an interaction with active sites of adsorbent and enhance the dye mobility to penetrate inside the adsorbent's pores [20].

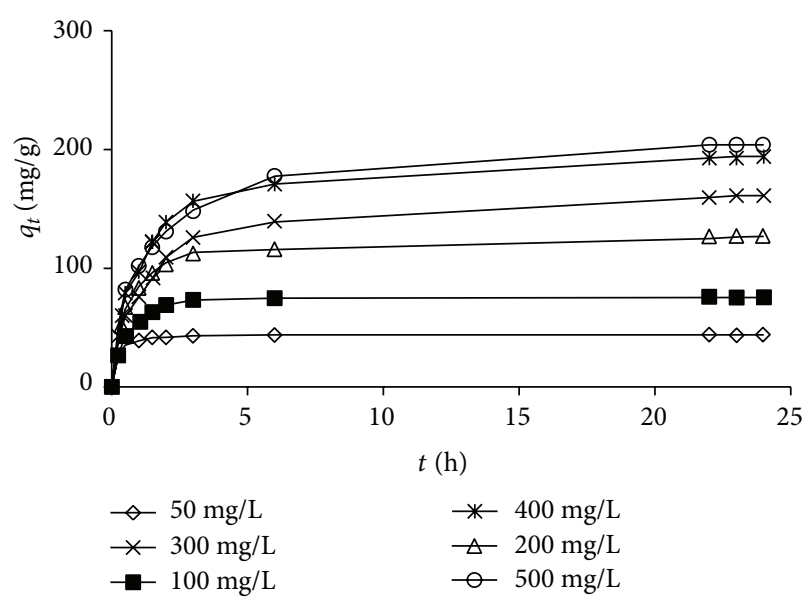

FIGURE 2: RBBR adsorption uptake versus adsorption time at various initial concentrations at $30^{\circ} \mathrm{C}$ on PF-AC.

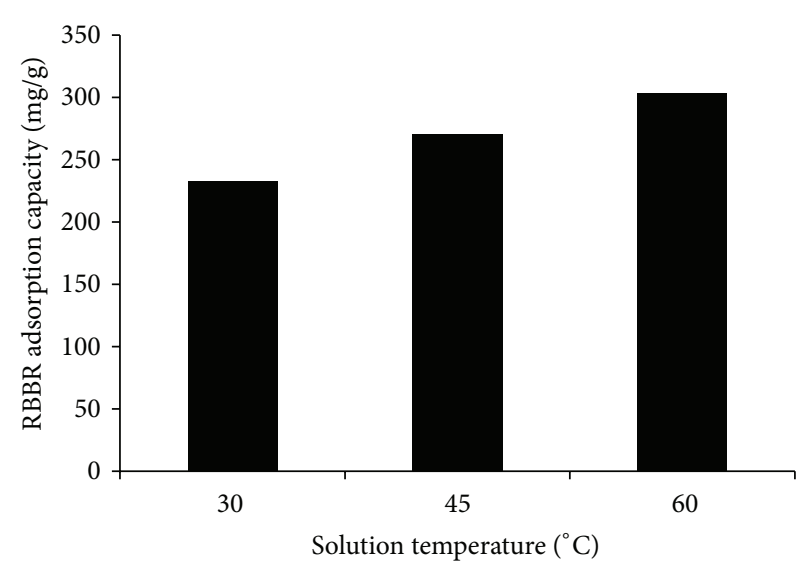

FIGURE 3: Effect of solution temperature on RBBR dye uptake at $100 \mathrm{mg} / \mathrm{L}$.

3.3. Effect of Initial $p H$. The effect of initial $\mathrm{pH}$ on the RBBR removal was studied at initial $\mathrm{pH}$ values of 3-11. Figure 4 shows the percentage removal of the RBBR was high at $\mathrm{pH}$ $3-5$ but decreased at $7-11 \mathrm{pH}$. The highest percentage of dye removal was $80.3 \%$ at $\mathrm{pH} 3$. At lower $\mathrm{pH}$, the attributed electrostatic interactions between the positively charged of $\mathrm{PF}-\mathrm{AC}$ and the negatively charged of RBBR dye anions prefer to give the high RBBR percentage removal [21]. Similar observation was obtained by other researchers $[22,23]$ where the highest percentage removal of RBBR dye onto activated carbon was obtained at lower $\mathrm{pH}$.

3.4. Adsorption Isotherm. The adsorption isotherm used to show the adsorption molecules distribute between the solid phase and liquid phase at adsorption equilibrium state. The Langmuir and Freundlich isotherms are the most frequently employed models. The linear regression is used to determine the best-fitting isotherm and the pertinency of isotherm equations is compared by evaluating the correlation coefficients, $R^{2}$. 
TABLE 1: Langmuir, Freundlich and Temkin isotherm model parameters and correlation coefficients for adsorption of RBBR on PF-AC at $30^{\circ} \mathrm{C}$.

\begin{tabular}{|c|c|c|c|c|c|c|}
\hline \multirow{3}{*}{ Activated carbon } & \multicolumn{6}{|c|}{ Isotherm } \\
\hline & \multicolumn{3}{|c|}{ Langmuir } & \multicolumn{3}{|c|}{ Freundlich } \\
\hline & $Q_{0}(\mathrm{mg} / \mathrm{g})$ & $K_{L}(\mathrm{~L} / \mathrm{mg})$ & $R^{2}$ & $K_{F}\left(\mathrm{mg} / \mathrm{g}(\mathrm{L} / \mathrm{mg})^{1 / n}\right)$ & $n$ & $R^{2}$ \\
\hline PF-AC & 232.59 & 0.211 & 0.986 & 3.72 & 2.417 & 0.996 \\
\hline
\end{tabular}

TABLE 2: Pseudo-first-order and pseudo-second-order kinetic model parameters for the adsorption of RBBR dye on PF-AC.

\begin{tabular}{lcccccc}
\hline \multirow{2}{*}{$C_{0}(\mathrm{mg} / \mathrm{L})$} & \multirow{2}{*}{$q_{e \text { exp. }}(\mathrm{mg} / \mathrm{g})$} & \multicolumn{2}{c}{ Pseudo-first-order kinetic model } & \multicolumn{3}{c}{ Pseudo-second-order kinetic model } \\
& & $q_{e 1}(\mathrm{mg} / \mathrm{g})$ & $k_{1}(1 / \mathrm{h})$ & $R^{2}$ & $q_{e 2}(\mathrm{mg} / \mathrm{g})$ & $k_{2}(\mathrm{~g} / \mathrm{mg} \mathrm{h})$ \\
\hline 50 & 43.8 & 22.098 & 1.2164 & 0.914 & 45.05 & 0.149 \\
100 & 75.2 & 66.646 & 1.1835 & 0.996 & 86.21 & 0.022 \\
200 & 126.8 & 98.810 & 0.7176 & 0.963 & 133.33 & 0.014 \\
300 & 161.1 & 141.119 & 0.4799 & 0.981 & 158.73 & 0.007 \\
400 & 194.0 & 167.436 & 0.5276 & 0.975 & 200.00 & 0.006 \\
500 & 204.0 & 167.319 & 0.4034 & 0.938 & 175.44 & 0.999 \\
\hline
\end{tabular}

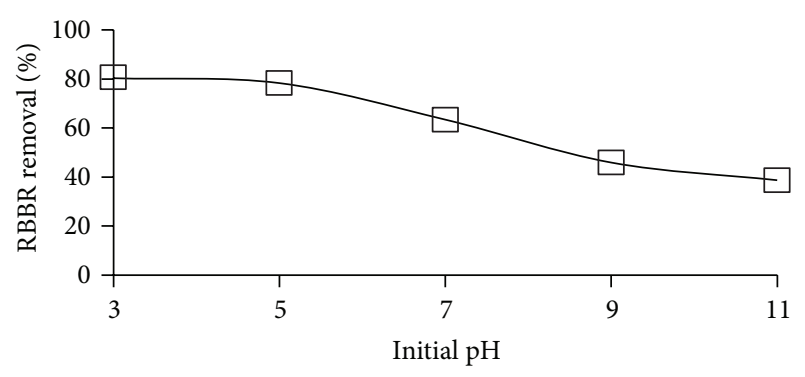

Figure 4: Effect of initial pH on RBBR removal by PF-AC.

Langmuir's isotherm model is based on the theory that adsorption energy is constant and uptake occurs on homogeneous surface by monolayer sorption. When the surface is covered by a monolayer of adsorbate, the adsorption goes on localized sites with no interaction between adsorbate molecules and that maximum adsorption occurs [24]. The linear form of Langmuir isotherm equation is given as

$$
\frac{C_{e}}{q_{e}}=\frac{1}{Q_{0} K_{L}}+\frac{1}{Q_{0}} C_{e},
$$

where $C_{e}(\mathrm{mg} / \mathrm{l})$ is the RBBR equilibrium concentration and $q_{e}(\mathrm{mg} / \mathrm{g})$ is the amount of RBBR adsorbed per unit mass of adsorbent. $Q_{0}(\mathrm{mg} / \mathrm{g})$ is the Langmuir constants related to adsorption capacity and $K_{L}(\mathrm{l} / \mathrm{mg})$ is rate of adsorption. The values of $Q_{0}$ and $K_{L}$ were calculated from the intercept and slope of linear plat and are presented in Table 1.

Freundlich model [25] is an empirical expression that is the earliest known relationship describing the sorption equation. This isotherm that takes into account a heterogeneous surface and multilayer adsorption to the binding sites located on the surface of the sorbent. The Freundlich model is expressed in the following equation:

$$
\log q_{e}=\log K_{f}+\frac{1}{n} \log C_{e},
$$

where $K_{f}$ and $n$ are indicative isotherm parameters of adsorption capacity and adsorption intensity, respectively. Generally, $n>1$ illustrates that adsorbate is favorably adsorbed on the adsorbent. The higher the number of $n$, the more favorable the adsorption and stronger the adsorption intensity [16].

From Table 1 Freundlich model gave higher $R^{2}$ values (0.996) than Langmuir model (0.986), which indicate that PF-AC adsorption of RBBR was made up of heterogeneous surface and multilayer adsorption [26]. This result is similar to other works on reactive dye adsorption by activated carbon prepared from coir pith [27], babassu coconut mesocarp [28], and "waste" wood-shaving bottom ash [29].

3.5. Adsorption Kinetics. Kinetics adsorption data of RBBR dye on PF-AC was analyzed using two kinetic models: pseudo-first-order and pseudo-second-order. The pseudofirst-order kinetic model is shown by the following equation [30]:

$$
\ln \left(q_{e}-q_{t}\right)=\ln q_{e}-k_{1} t
$$

where $q_{e}$ and $q_{t}(\mathrm{mg} / \mathrm{g})$ are the amount of adsorbate adsorbed at equilibrium and at any time, $t(\mathrm{~h})$, respectively, and $k_{1}$ $(1 / h)$ is the adsorption rate constant. Figure 5 shows that the linear plot of $\ln \left(q_{e}-q_{t}\right)$ versus $t$ gives a gradient of $k_{1}$ and intercept at $\ln q_{e}$. Table 2 shows the values of $k_{1}$ and $R^{2}$ obtained from the plots at $30^{\circ} \mathrm{C}$, where the $R^{2}$ value of pseudo-first-order model did not fit well with the whole range of contact time. In addition, the experimental $q_{e}$ values did not match with the calculated values obtained from the linear plots. Therefore, the adsorption of RBBR on the PF-AC was not following pseudo-first-order model. The kinetic data were further treated with the pseudo-second order kinetic model.

The pseudo-second-order model predicts the performance over the total range adsorption and is expressed as [31]

$$
\frac{t}{q_{t}}=\frac{1}{k_{2} q_{e}^{2}}+\frac{1}{q_{e}} t,
$$




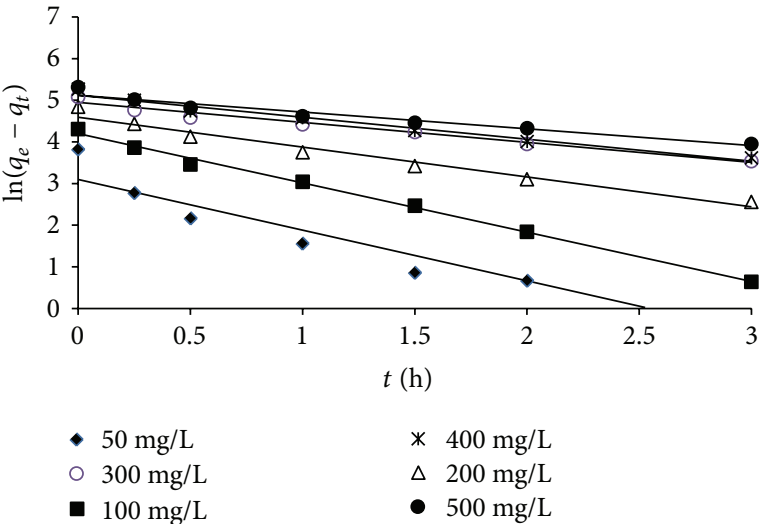

FIGURE 5: Plots of pseudo-first-order for RBBR adsorption on PFAC.

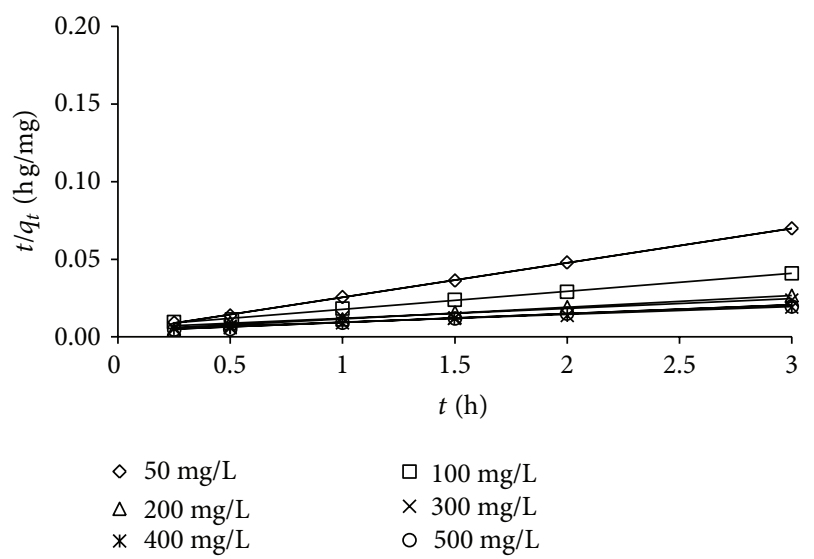

FIGURE 6: Plots of pseudo-second-order for RBBR adsorption on PF-AC.

where $k_{2}(\mathrm{~g} / \mathrm{mg} \mathrm{h})$ is the rate constant of second-order adsorption. Figure 6 shows that the linear plot of $t / q_{t}$ versus $t$ gave $1 / k_{2} q_{e}^{2}$ as the intercept and $1 / q_{e}$ as the gradient. From Table 2 , the $R^{2}$ for the pseudo-second-order adsorption shows the highest value mostly 0.99 which indicates that this kinetic model has a good relation and is consistent between the experimental and the calculated $q_{e}$ values. It also shows that pseudo-second-order model adsorption is predominant. The adsorption can be seen as the rate-limiting step that controls the biosorption process.

3.6. Adsorption Mechanism. The kinetic results were further analyzed by using the intraparticle diffusion model by using the following equation:

$$
q_{t}=k_{p i} t^{1 / 2}+C_{i}
$$

where $k_{p i}\left(\mathrm{mg} / \mathrm{g} \mathrm{h}^{1 / 2}\right)$ is the rate parameter of stage $i$ which is obtained from the gradient of the $q_{t}$ versus $t^{1 / 2}$ straight line. $C_{i}$ is the boundary layer effect which means that the larger the intercept, the greater the contribution of the surface sorption

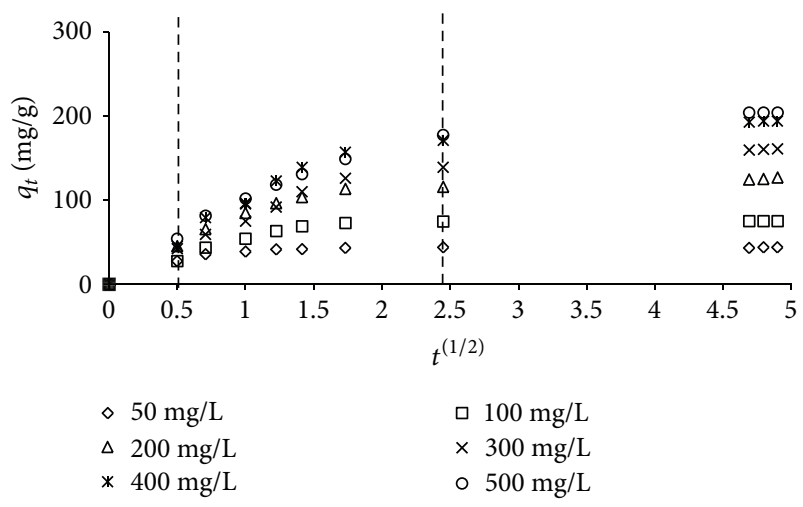

FIGURE 7: Intraparticle diffusion model for RBBR adsorption on PFAC.

in the rate-controlling step [21]. The intraparticle diffusion should occur if the $q_{t}$ versus $t^{1 / 2}$ is linear.

Figure 7 shows three stages of RBBR adsorption onto PF-AC. First sharp region indicates the strong electrostatic attraction between dye molecules and external surface adsorbent. Second stage shows a gradual adsorption stage. It is assigned the diffusion of dye molecule through the pores of adsorbent [32]. The third region indicates the final equilibrium stage and the intraparticle diffusion slowdown due to the extremely low adsorbate concentration in the solution [33]. For RBBR with low initial concentrations $(0-100 \mathrm{mg} / \mathrm{L})$, this third region did slightly change as most of the dye molecules were already adsorbed as early in 1.5 hour of adsorption time. Referring to Figure 7, the plots were not linear over the whole time range. In other words, intraparticle diffusion involves the rate limiting step and boundary control in process [34]. The values of $k_{p i}, C_{i}$, and $R^{2}$ of three regions were obtained from the plots reported in Table 3. It showed that $k_{p i}$ values for the three regions increase as the RBBR initial concentrations increase.

3.7. Adsorption Thermodynamics. Thermodynamic parameters provide information of inherent energetic changes associated with adsorption. The thermodynamic adsorption parameters to be characterized are standard enthalpy $\left(\Delta H^{0}\right)$, standard free energy $\left(\Delta G^{0}\right)$, and standard entropy $\left(\Delta S^{0}\right)$. The values of $\Delta H^{0}, \Delta S^{0}$ and $\Delta G^{0}$ are calculated by using (9) and (10):

$$
\begin{aligned}
\ln K_{L} & =\frac{\Delta S^{0}}{R}-\frac{\Delta H^{0}}{R T} \\
\Delta G^{0} & =-R T \ln K_{L}
\end{aligned}
$$

where $R(8.314 \mathrm{~J} / \mathrm{mol} \mathrm{K})$ is the universal gas constant, $T(\mathrm{~K})$ is the absolute solution temperature, and $K_{L}(\mathrm{~L} / \mathrm{mg})$ is the Langmuir isotherm constant. For the $\Delta H^{0}$ and $\Delta S^{0}$ can be evaluated from the gradient and intercept of $\ln K_{L}$ versus $1 / T$, 
TABLE 3: Intraparticle diffusion model constants for the adsorption of RBBR on PF-AC.

\begin{tabular}{lccccccccc}
\hline \multirow{2}{*}{$C_{0}(\mathrm{mg} / \mathrm{L})$} & \multicolumn{9}{c}{ Intraparticle diffusion model } \\
& $k_{p 1}\left(\mathrm{mg} / \mathrm{g} \mathrm{h}^{1 / 2}\right)$ & $k_{p 2}\left(\mathrm{mg} / \mathrm{g} \mathrm{h}^{1 / 2}\right)$ & $k_{p 3}\left(\mathrm{mg} / \mathrm{g} \mathrm{h}^{1 / 2}\right)$ & $C_{1}$ & $C_{2}$ & $C_{3}$ & $\left(R_{1}\right)^{2}$ & $\left(R_{2}\right)^{2}$ & $\left(R_{3}\right)^{2}$ \\
\hline 50 & 55.6 & 7.14 & - & 0 & 29.62 & 43.8 & 1 & 0.690 \\
100 & 55.0 & 23.29 & 0.21 & 0 & 27.89 & 74.18 & 1 & 0.780 & 0.995 \\
200 & 86.0 & 36.24 & 4.37 & 0 & 42.34 & 105.05 & 1 & 0.798 & 0.994 \\
300 & 81.0 & 52.12 & 9.24 & 0 & 24.44 & 116.28 & 1 & 0.929 & 0.999 \\
400 & 92.8 & 63.59 & 9.67 & 0 & 33.81 & 147.08 & 1 & 0.896 & 0.999 \\
500 & 107.0 & 61.80 & 11.23 & 0 & 36.44 & 150.08 & 1 & 0.958 & 0.995 \\
\hline
\end{tabular}

TABLE 4: Thermodynamic parameters for the adsorption of RBBR on PF-AC.

\begin{tabular}{lccccc}
\hline \multirow{2}{*}{$\Delta H^{0}(\mathrm{~kJ} / \mathrm{mol})$} & \multirow{2}{*}{$\Delta S^{0}(\mathrm{~J} / \mathrm{mol} \mathrm{K})$} & \multirow{2}{*}{$E_{a}(\mathrm{~kJ} / \mathrm{mol})$} & \multicolumn{4}{c}{$\Delta G^{0}(\mathrm{~kJ} / \mathrm{mol})$} \\
& & & $303 \mathrm{~K}$ & $318 \mathrm{~K}$ & $333 \mathrm{~K}$ \\
\hline 6.78 & -9.61 & 8.51 & 9.72 & 9.81 & 10.04 \\
\hline
\end{tabular}

respectively. To obtain the activation energy of adsorption, Arrhenius equation was applied using

$$
\ln k_{2}=\ln A-\frac{E_{a}}{R T}
$$

where $k_{2}(\mathrm{~g} / \mathrm{mgh})$ is the rate constant evaluate from the pseudo-second-order kinetic model, $E_{a}(\mathrm{~kJ} / \mathrm{mol})$ is the Arrhenius activation energy of adsorption and $A$ is the Arrhenius factor. When $\ln k_{2}$ was plotted against $1 / T$, a straight line with gradient of $-E_{a} / R$ was obtained.

Table 4 reported the values of $\Delta H^{0}, \Delta S^{0}, \Delta G^{0}$, and $E_{a}$ for adsorption of RBBR dye on PF-AC. The positive $\Delta H^{0}$ value shows that the adsorption of RBBR dye onto PRAC was endothermic in nature, which supported the results obtained earlier where the RBBR dye uptakes increase with increase in solution temperature. The negative value of $\Delta S^{0}$ describes decreasing degree of freedom and randomness during the adsorption process at the solid-liquid interface with some structural changes in the adsorbate and adsorbent. This phenomenon had also been observed in the adsorption of azo-dye Orange II by titania aerogel [35] and direct dyes by carbon nanotubes [36]. For the standard free energy, $\Delta G^{0}$ values were positive which describe the condition of nonspontaneous nature of the adsorption processes at the range of temperature studied. The $E_{a}$ value was positive and lower than $40 \mathrm{~kJ} / \mathrm{mol}$, indicating that the feasibility of the adsorption process and adsorption process was physically controlled, respectively [37].

\section{Conclusion}

The adsorption of RBBR onto PF-AC was found to increase with increase in initial dye concentration, contact time, and solution temperature. The adsorption of RBBR on PF-AC was favored at acidic medium. The Freundlich model and the pseudo-second-order kinetic model were fits well to the adsorption equilibrium and kinetic data, respectively. Thermodynamic adsorption studies indicated that the adsorption process was endothermic, and nonspontaneous reaction in nature and rate limiting step in RBBR was physically controlled.

\section{Conflict of Interests}

The authors declare that there is no conflict of interests regarding the publication of this paper.

\section{Acknowledgments}

The authors gratefully acknowledge the financial support received from MyBrain provided by Ministry of Higher Education Malaysia and Centre of Research and Innovation Management (CRIM) Universiti Teknikal Malaysia Melaka.

\section{References}

[1] S. Senthilkumaar, P. Kalaamani, K. Porkodi, P. R. Varadarajan, and C. V. Subburaam, "Adsorption of dissolved reactive red dye from aqueous phase onto activated carbon prepared from agricultural waste," Bioresource Technology, vol. 97, no. 14, pp. 1618-1625, 2006.

[2] K. Murugesan, I.-H. Nam, Y.-M. Kim, and Y.-S. Chang, "Decolorization of reactive dyes by a thermostable laccase produced by Ganoderma lucidum in solid state culture," Enzyme and Microbial Technology, vol. 40, no. 7, pp. 1662-1672, 2007.

[3] E. A. el-Sharkawy, A. Y. Soliman, and K. M. al-Amer, "Comparative study for the removal of methylene blue via adsorption and photocatalytic degradation," Journal of Colloid and Interface Science, vol. 310, no. 2, pp. 498-508, 2007.

[4] V. Dulman and S. M. Cucu-Man, "Sorption of some textile dyes by beech wood sawdust," Journal of Hazardous Materials, vol. 162, no. 2-3, pp. 1457-1464, 2009.

[5] Ö. Tunç, H. Tanaci, and Z. Aksu, "Potential use of cotton plant wastes for the removal of Remazol Black B reactive dye," Journal of Hazardous Materials, vol. 163, no. 1, pp. 187-198, 2009.

[6] P. Baskaralingam, M. Pulikesi, V. Ramamurthi, and S. Sivanesan, "Modified hectorites and adsorption studies of a reactive dye," Applied Clay Science, vol. 37, no. 1-2, pp. 207-214, 2007.

[7] F. O. Okeola and E. O. Odebunmi, "Freundlich and Langmuir isotherms parameters for adsorption of methylene blue by activated carbon derived from agrowastes," Advances in Natural and Applied Sciences, vol. 4, no. 3, pp. 281-288, 2010.

[8] V. Vadivelan and K. V. Kumar, "Equilibrium, kinetics, mechanism, and process design for the sorption of methylene blue onto rice husk," Journal of Colloid and Interface Science, vol. 286, no. 1, pp. 90-100, 2005. 
[9] A. S. Bhatt, P. L. Sakaria, M. Vasudevan et al., "Adsorption of an anionic dye from aqueous medium by organoclays: equilibrium modeling, kinetic and thermodynamic exploration," $R S C$ Advances, vol. 2, no. 23, pp. 8663-8671, 2012.

[10] B. H. Hameed, A. L. Ahmad, and K. N. A. Latiff, "Adsorption of basic dye (methylene blue) onto activated carbon prepared from rattan sawdust," Dyes and Pigments, vol. 75, no. 1, pp. 143149, 2007.

[11] M. J. Iqbal and M. N. Ashiq, "Adsorption of dyes from aqueous solutions on activated charcoal," Journal of Hazardous Materials, vol. 139, no. 1, pp. 57-66, 2007.

[12] A. Özcan, E. M. Öncü, and A. S. Özcan, "Adsorption of acid blue 193 from aqueous solutions onto DEDMA-sepiolite," Journal of Hazardous Materials, vol. 129, no. 1-3, pp. 244-252, 2006.

[13] V. K. Gupta and S. Suhas, "Application of low-cost adsorbents for dye removal-a review," Journal of Environmental Management, vol. 90, no. 8, pp. 2313-2342, 2009.

[14] S. G. Herawan, M. A. Ahmad, A. Putra, and A. A. Yusof, "Effect of $\mathrm{CO}_{2}$ flow rate on the pinang frond-based activated carbon for methylene blue removal," The Scientific World Journal, vol. 2013, Article ID 545948, 6 pages, 2013.

[15] W.-T. Tsai and H.-R. Chen, "Removal of malachite green from aqueous solution using low-cost chlorella-based biomass," Journal of Hazardous Materials, vol. 175, no. 1-3, pp. 844-849, 2010.

[16] M. A. Ahmad and R. Alrozi, "Removal of malachite green dye from aqueous solution using rambutan peel-based activated carbon: equilibrium, kinetic and thermodynamic studies," Chemical Engineering Journal, vol. 171, no. 2, pp. 510-516, 2011.

[17] O. S. Bello, M. A. Ahmad, and N. Ahmad, "Adsorptive features of banana (Musa paradisiaca) stalk-based activated carbon for malachite green dye removal," Chemistry and Ecology, vol. 28, no. 2, pp. 153-167, 2012.

[18] A. T. M. Din, B. H. Hameed, and A. L. Ahmad, "Batch adsorption of phenol onto physiochemical-activated coconut shell," Journal of Hazardous Materials, vol. 161, no. 2-3, pp. $1522-$ 1529, 2009.

[19] B. H. Hameed and M. I. el-Khaiary, "Batch removal of malachite green from aqueous solutions by adsorption on oil palm trunk fibre: equilibrium isotherms and kinetic studies," Journal of Hazardous Materials, vol. 154, no. 1-3, pp. 237-244, 2008.

[20] M. A. Ahmad and N. K. Rahman, "Equilibrium, kinetics and thermodynamic of Remazol Brilliant Orange 3R dye adsorption on coffee husk-based activated carbon," Chemical Engineering Journal, vol. 170, no. 1, pp. 154-161, 2011.

[21] B. H. Hameed, A. A. Ahmad, and N. Aziz, "Adsorption of reactive dye on palm-oil industry waste: equilibrium, kinetic and thermodynamic studies," Desalination, vol. 247, no. 1-3, pp. 551-560, 2009.

[22] A. Ergene, K. Ada, S. Tan, and H. Katircioğlu, "Removal of Remazol Brilliant Blue R dye from aqueous solutions by adsorption onto immobilized Scenedesmus quadricauda: equilibrium and kinetic modeling studies," Desalination, vol. 249, no. 3, pp. 1308-1314, 2009.

[23] P. Sathishkumar, M. Arulkumar, and T. Palvannan, "Utilization of agro-industrial waste Jatropha curcas pods as an activated carbon for the adsorption of reactive dye Remazol Brilliant Blue R (RBBR)," Journal of Cleaner Production, vol. 22, no. 1, pp. 6775, 2012.

[24] I. Langmuir, "The adsorption of gases on plane surfaces of glass, mica and platinum," Journal of the American Chemical Society, vol. 40, no. 9, pp. 1361-1403, 1918.
[25] H. M. F. Freundlich, "Over the adsorption in solution," The Journal of Physical Chemistry, vol. 385, pp. 385-470, 1906.

[26] A. Özcan, Ç. Ömeroğlu, Y. Erdoğan, and A. S. Özcan, "Modification of bentonite with a cationic surfactant: an adsorption study of textile dye Reactive Blue 19," Journal of Hazardous Materials, vol. 140, no. 1-2, pp. 173-179, 2007.

[27] K. Santhy and P. Selvapathy, "Removal of reactive dyes from wastewater by adsorption on coir pith activated carbon," Bioresource Technology, vol. 97, no. 11, pp. 1329-1336, 2006.

[28] A. P. Vieira, S. A. A. Santana, C. W. B. Bezerra et al., "Kinetics and thermodynamics of textile dye adsorption from aqueous solutions using babassu coconut mesocarp," Journal of Hazardous Materials, vol. 166, no. 2-3, pp. 1272-1278, 2009.

[29] P. Leechart, W. Nakbanpote, and P. Thiravetyan, "Application of "waste" wood-shaving bottom ash for adsorption of azo reactive dye," Journal of Environmental Management, vol. 90, no. 2, pp. 912-920, 2009.

[30] S. Largergren, "Zur theorie der sogenannten adsorption geloster stoffe," Kungliga Svenska Vetenskapsakademiens Handlingar, vol. 24, pp. 1-39, 1898.

[31] Y. S. Ho and G. McKay, "Pseudo-second order model for sorption processes," Process Biochemistry, vol. 34, no. 5, pp. 451$465,1999$.

[32] B. H. Hameed and M. I. el-Khaiary, "Equilibrium, kinetics and mechanism of malachite green adsorption on activated carbon prepared from bamboo by $\mathrm{K}_{2} \mathrm{CO}_{3}$ activation and subsequent gasification with $\mathrm{CO}_{2}$," Journal of Hazardous Materials, vol. 157, no. 2-3, pp. 344-351, 2008.

[33] L. Wang, J. Zhang, R. Zhao, C. Li, Y. Li, and C. Zhang, "Adsorption of basic dyes on activated carbon prepared from Polygonum orientale Linn: equilibrium, kinetic and thermodynamic studies," Desalination, vol. 254, no. 1-3, pp. 68-74, 2010.

[34] I. A. W. Tan, A. L. Ahmad, and B. H. Hameed, "Adsorption isotherms, kinetics, thermodynamics and desorption studies of 2,4,6-trichlorophenol on oil palm empty fruit bunch-based activated carbon," Journal of Hazardous Materials, vol. 164, no. 2-3, pp. 473-482, 2009.

[35] L. Abramian and H. el-Rassy, "Adsorption kinetics and thermodynamics of azo-dye Orange II onto highly porous titania aerogel," Chemical Engineering Journal, vol. 150, no. 2-3, pp. 403-410, 2009.

[36] C.-Y. Kuo, C.-H. Wu, and J.-Y. Wu, "Adsorption of direct dyes from aqueous solutions by carbon nanotubes: determination of equilibrium, kinetics and thermodynamics parameters," Journal of Colloid and Interface Science, vol. 327, no. 2, pp. 308-315, 2008.

[37] H. Nollet, M. Roels, P. Lutgen, P. van der Meeren, and W. Verstraete, "Removal of PCBs from wastewater using fly ash," Chemosphere, vol. 53, no. 6, pp. 655-665, 2003. 

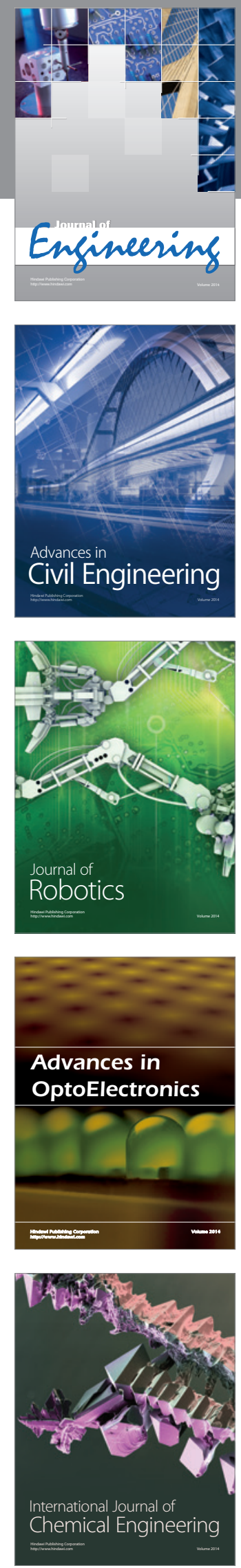

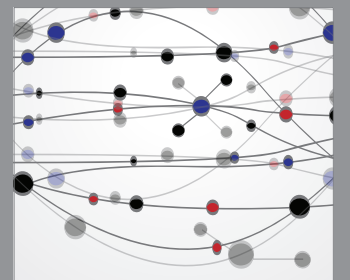

The Scientific World Journal
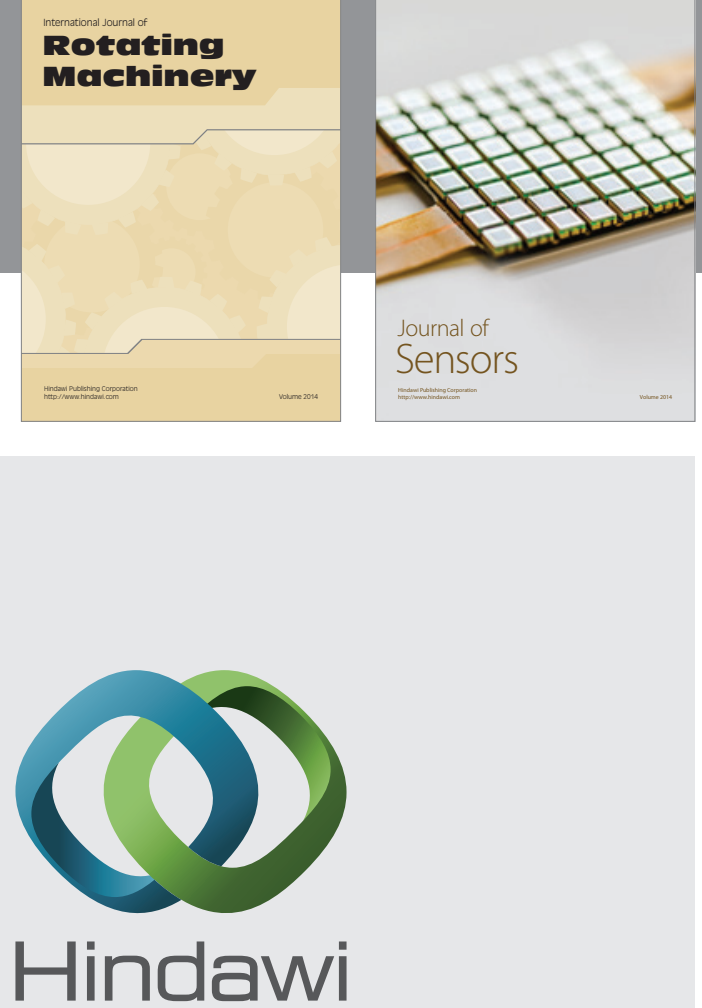

Submit your manuscripts at http://www.hindawi.com
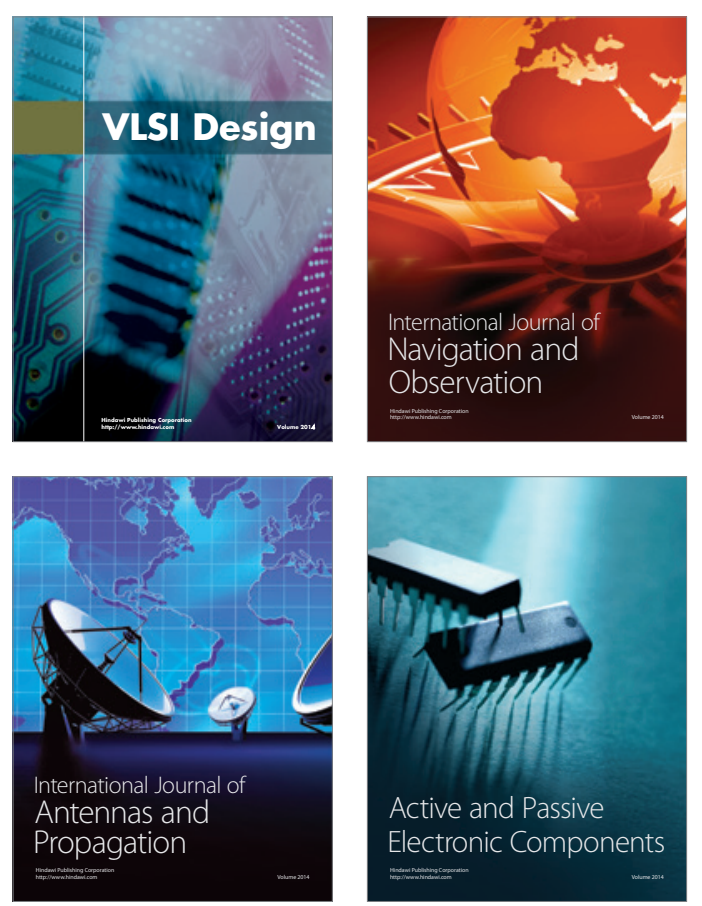
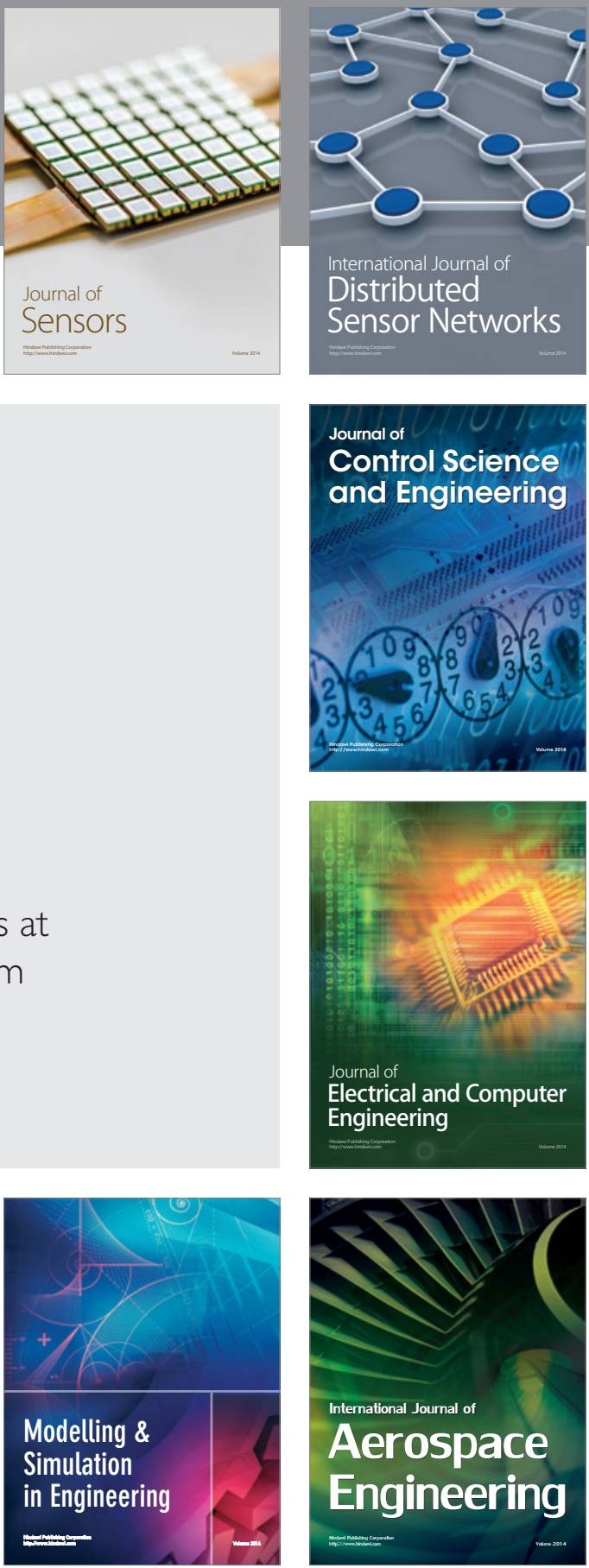

Journal of

Control Science

and Engineering
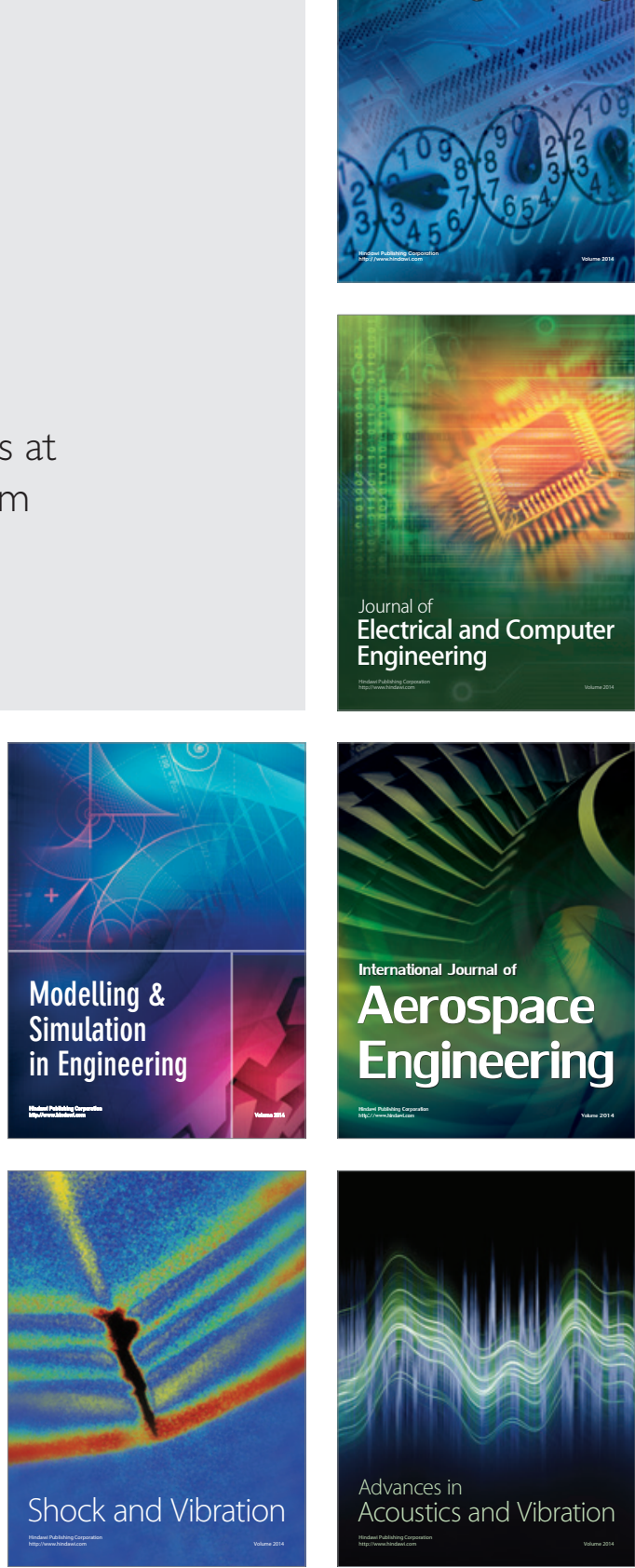